Research Paper

\title{
Simultaneous and successive inoculations of yeasts and lactic acid bacteria on the fermentation of an unsulfited Tannat grape must
}

\author{
Viviana Muñoz, Bruno Beccaria, Eduardo Abreo \\ Laboratorio de Microbiología Enológica, Escuela Superior de Vitivinicultura, Canelones, Uruguay.
}

Submitted: July 22, 2012; Approved: September 9, 2013.

\begin{abstract}
Interactions between yeasts and lactic acid bacteria are strain specific, and their outcome is expected to change in simultaneous alcoholic - malolactic fermentations from the pattern observed in successive fermentations. One Oenococcus oeni strain Lalvin VP41'TM was inoculated with two Saccharomyces cerevisiae strains either simultaneously, three days after the yeast inoculation, or when alcoholic fermentation was close to finish. Early bacterial inoculations with each yeast strain allowed for the growth of the bacterial populations, and the length of malolactic fermentation was reduced to six days. Alcoholic fermentation by Lalvin ICV D80® yeast strain left the highest residual sugar, suggesting a negative effect of the bacterial growth and malolactic activity on its performance. In sequential inoculations the bacterial populations did not show actual growth with either yeast strain. In this strategy, both yeast strains finished the alcoholic fermentations, and malolactic fermentations took longer to finish. Lalvin ICV D80® allowed for higher viability and activity of the bacterial strain than Fermicru UY4® under the three inoculation strategies. This was beneficial for the sequential completion of both fermentations, but negatively affected the completion of alcoholic fermentation by Lalvin ICV D $80 \AA$ in the early bacteria additions. Conversely, Fermicru UY4 ${ }^{\circ}$, which was rather inhibitory towards the bacteria, favored the timely completion of both fermentations simultaneously. As bacteria in early inoculations with low or no $\mathrm{SO}_{2}$ addition can be expected to multiply and interact with fermenting yeasts, not only are the yeast-bacterium strains combination and time point of the inoculation to be considered, but also the amount of bacteria inoculated.
\end{abstract}

Key words: Saccharomyces, Oenococcus, co-inoculation.

\section{Introduction}

Malolactic fermentation (MLF), carried out by Oenococcus oeni and other lactic acid bacteria (LAB), implies the decarboxilation of L-malic acid and the production of L-latic acid and carbon dioxide (Lafon-Lafourcade et al., 1983). MLF usually takes place after alcoholic fermentation (AF) has finished and when the native population of LAB has increased. After MLF, the wine shows higher $\mathrm{pH}$ and aroma modifications. MLF is considered a desirable biological deacidification process that increases microbial stability in low $\mathrm{pH}$ wines due to the reduction in the amount of malic acid that is no longer available as substrate for undesirable microorganisms in later stages of wine production. In high $\mathrm{pH}$ wines MLF can be favored for stylistic reasons but it can produce microbial instability due the $\mathrm{pH}$ increment and lowered antimicrobial activity of $\mathrm{SO}_{2}$ (Davis et al., 1985). Citric acid can also be metabolized by $\mathrm{LAB}$, producing acetic acid and diacetyl at levels that can have an impact on wine aroma (Lonvaud-Funel, 1999). If hexose sugars are available for heterofermentative LAB like O. oeni, D-lactic acid, $\mathrm{CO}_{2}$, and high levels of acetic acid can be produced, affecting the alcoholic fermentation, the aroma and taste of the resulting wine (Davis et al., 1985).

In sequential inoculations of selected $O$. oeni strains, MLF can be slow or incomplete due to the high ethanol content, low $\mathrm{pH}$, antimicrobial activity of $\mathrm{SO}_{2}$ and the low nutritional status of wine. Therefore wine intended to undergo MLF is kept with low levels of $\mathrm{SO}_{2}$ for extended peri-

Send correspondence to E. Abreo. Laboratorio De Microbiología Enológica, Escuela Superior de Vitivinicultura, Ruta 48 El Colorado, Canelones, Uruguay. E-mail: eabreo@utu.edu.uy. 
ods (Alexandre et al., 2004), which increases the risk of spoilage by other wine microorganisms like Brettanomyces spp. (Gerbaux et al., 2009). The compatibility of selected strains of $S$. cerevisiae and $O$. oeni has also been taken into account to improve the occurrence of sequential malolactic fermentations in a safe, predictable way (Arnink and Henick-Kling, 2005; Patynowski et al., 2002) . However, the variable chemical composition of wines made from different cultivars and in different years can still pose a challenge to the occurrence of MLF even when compatible yeast - bacterium strains are used (Arnink and HenickKling, 2005).

Because of this, the inoculation of $O$. oeni along with $S$. cerevisiae in the must aiming at inducing simultaneous MLF and AF has been proposed to accelerate wine processing by anticipating the time and reducing the length of MLF (Beelman and Kunkee, 1985; King and Beelman 1986; Jussier et al., 2006; Zapparoli et al., 2009; Abreo and Echeverry, 2010; Azzolini et al., 2010). In this strategy, $O$. oeni has been inoculated in the must together or shortly after $S$. cerevisiae, and MLF has been completed concurrently with $\mathrm{AF}$, in a shorter time period than in sequential inoculations. Experimental wines from simultaneous fermentations have shown a faster consumption of malic acid, with no relevant increases of residual hexoses, acetic or lactic acids (Pan et al., 2011; Izquierdo Cañas et al., 2012; Jussier et al., 2006). However, in spite of its many advantages regarding wine processing, this strategy has not been widely implemented as several questions remain regarding the most suitable time for the bacterial addition (coincidently with the yeast or in the middle of alcoholic fermentation have both been considered as simultaneous inoculations) and the erratic interactions between $S$. cerevisiae and $O$. oeni strains in fermenting musts. Whereas in sequential inoculations, the effect of some $S$. cerevisiae strains can vary from stimulatory to inhibitory towards strains of $O$. oeni (Nehme et al., 2008), the outcome of these strain specific yeast-bacteria interactions could be shifted in the must, and yeasts might even be inhibited by some LAB. If this was the case, the concern that the metabolism of must sugars by heterofermentative LAB could lead to inacceptable levels of $\mathrm{D}$ - lactic and acetic acid might become real (Mendoza et al., 2011).

The aim of this study was to compare the performance of two yeast/bacterium combinations (one of known compatibility for sequential fermentations) when inoculated in three different settings: both simultaneously, yeast first and bacteria three days after, or yeast followed by the bacteria when $\mathrm{AF}$ was close to finish.

\section{Materials and Methods}

\section{Winemaking}

One hundred $\mathrm{kg}$ of grapes of $V$. vinifera $\mathrm{cv}$. Tannat were hand harvested from the vineyard at the Escuela Supe- rior de Vitivinicultura in El Colorado, Canelones, Uruguay. Grape bunches were destemmed and crushed in a stainless steel crusher to obtain $60 \mathrm{~L}$ of must. The juice was separated from the marc and it was analyzed for its initial composition. Total soluble solids were determined by refractometry, initial malic acid was analyzed enzymatically (Roche) in a Shimadzu UV Mini 1240 spectrophotometer at $340 \mathrm{~nm}$, yeast assimilable nitrogen (YAN) was determined by the formol method, total $\mathrm{SO}_{2}$ was determined by Ripper method using iodine, titratable acidity (TA) was measured by titration and expressed as $\mathrm{g} \mathrm{H}_{2} \mathrm{SO}_{4} / \mathrm{L}$, volatile acidity (VA) was measured by distillation and expressed as $\mathrm{g} \mathrm{H}_{2} \mathrm{SO}_{4} / \mathrm{L}$, alcohol was measured by distillation followed by hydrometry and expressed as percentage $\mathrm{v} / \mathrm{v}$ (Zoecklein et al., 1995), $\mathrm{pH}$ was measured with an Orion $410 \mathrm{pH}$ meter.

Must soluble solids were 23 Brix, malic acid was $5.2 \mathrm{~g} / \mathrm{L}, \mathrm{pH}$ was 3.5 , TA was $5.4 \mathrm{~g} \mathrm{H}_{2} \mathrm{SO}_{4} / \mathrm{L}$, YAN was $103.6 \mathrm{mg} / \mathrm{L}$, total $\mathrm{SO}_{2}$ and VA were null. Nitrogen was supplemented to the must $(430 \mathrm{mg} / \mathrm{L}$ of $30 \% \mathrm{~N}$ Abavin Nut $\AA$ ) before fermentation to reach $233 \mathrm{mg} / \mathrm{L}$ YAN, whereas $\mathrm{SO}_{2}$ was not added to the must or wine until after the completion of both fermentations.

The juice was racked off the marc after 4 hours of maceration at $10^{\circ} \mathrm{C}$, and it was divided in volumes of $2.1 \mathrm{~L}$ into $3 \mathrm{~L}$ plastic containers. Treatments were carried out in triplicate and consisted on the simultaneous inoculation of yeast-bacterium combinations (simultaneous), bacterial inoculation three days after initial yeast inoculation (midfermentation), or initial inoculation of yeast followed by bacterial inoculation when alcoholic fermentation was close to finish (sequential). Control wines were inoculated with the yeast strains in triplicate, with no inoculation of bacteria, to set a baseline to compare malic acid degradation by the inoculated LAB and native LAB.

Alcoholic fermentation was monitored daily by changes in density with a hydrometer, and malolactic fermentation was monitored by thin layer chromatography (TLC) every two days. Residual malic acid, D- and L-lactic acid, glucose and fructose were enzymatically measured together with VA in the finished wines after sulfiting.

\section{Microorganisms}

Commercially available Saccharomyces cerevisiae strains used for must inoculation were Lalvin ICV D80® -LD80- (Lallemand) originally isolated from the Rhône Valley and Fermicru UY4® -FUY4- (DSM), an autochthonous local strain originally isolated from a $V$. vinifera cv. Tannat block at the Escuela Superior de Vitivinicultura in Uruguay (Martínez et al., 2007). The O. oeni strain used for inoculations was Lalvin VP41 one step, originally isolated in Italy and usually inoculated after AF in wines fermented with yeast LD80 in Uruguay. Rehydration and acclimatization procedures were done according to manufacturers' instructions. The temperature of the must at the 
time of inoculation was $20.5^{\circ} \mathrm{C}$, and it ranged between $18{ }^{\circ} \mathrm{C}$ and $21{ }^{\circ} \mathrm{C}$ during the experiment.

S. cerevisiae viable culturable population was determined by spread plating a serial dilution of must or wine, using a sterile solution of $0.9 \% \mathrm{w} / \mathrm{v} \mathrm{NaCl}$ as diluent, on WL medium (Wallerstein Laboratories, Oxoid Ltd., Hampshire, England), while $O$. oeni viable culturable population was determined by pour plating a serial dilution of must or wine, using the same diluent, on TSA medium (Tryptone Soya Agar, Oxoid Ltd., Hampshire, England) supplemented with $25 \% \mathrm{v} / \mathrm{v}$ fresh tomato juice and $0.01 \% \mathrm{w} / \mathrm{v}$ cycloheximide. Samples were taken every two days during alcoholic fermentation and every three days after that moment. Plates were incubated at $28{ }^{\circ} \mathrm{C}$ and colony forming units (cfu) were counted after three and seven days for yeast and bacteria respectively.

\section{Statistical analysis}

All measures are the average of three replicates. Statistical effect of main factors (yeast strain and time of bacteria addition) and their interactions on key wine components was assessed by a two ways ANOVA $(p=0.05)$. HolmSidak test was used for pairwise comparisons between treatments (Sigma Stat software).

\section{Results}

\section{Length of fermentations}

Alcoholic fermentation was finished in all treatments 16 days after yeast inoculation as determined by three consecutive hydrometer readings of density below $1000 \mathrm{~g} / \mathrm{L}$. According to the disappearance of the malic acid spot on TLC $(<0.2 \mathrm{~g} / \mathrm{L})$ malolactic fermentation took 6 days since the simultaneous inoculation of bacteria with both yeast strains, and 7 days since the mid-fermentation inoculation of bacteria. Since sequential bacterial additions on day 15 , MLF took 20 and 14 days for the FUY4 and LD80 fermented wines, while it took 23 and 25 days for control wines respectively (Table1).

\section{S. cerevisiae and $O$. oeni populations}

The simultaneous and mid-fermentation inoculation of the bacterium with both yeast strains reduced the growth of the yeast populations. For both yeast-bacterium combinations, the viable population of $S$. cerevisiae showed a slower growth and a lower plateau (Figure 1A and Figure 1B). The negative effect caused by the simultaneous inoculation on yeast growth was more pronounced on LD80 than on the FUY4 cells. In both, the population peaked on day five reaching $4 \times 10^{9}$, but after that day, the LD80 population fell consistently, whereas the population of FUY4 kept growing until it reached $7 \times 10^{9}$ on day nine since inoculation. Still, the slope of the curve indicated that its growth was slower than in the control fermentations (Figure 1A).
Similarly, in the treatments with bacteria inoculated on the third day after fermentation had started, the introduction of the bacteria inocula was followed by a reduction in yeast viability for both yeast strains. However, the FUY4 population recovered viability in the following days (Figure $1 \mathrm{~A})$.

An effect of yeast strain on bacteria could also be observed (Figure 2). While the population of bacteria simultaneously inoculated with the LD80 showed a two days lag phase followed by four days of intense growth and eight days of milder growth, the bacteria inoculated with FUY4 showed an initial lag phase that took four days, followed by four days of intense growth and four days of milder growth. In the case of bacteria inoculated at mid-fermentation, there was an initial reduction in the viability or culturability of bacterial cells during two days. After that, bacteria inoculated with LD80 recovered the lost viability within two days and kept growing for eight days, whereas the bacteria inoculated with FUY4 recovered the lost viability in four days and then showed growth during six days.

When bacteria were inoculated after alcoholic fermentation, a similar trend could be observed (Figure 2). Initially, the bacteria inoculated with both yeasts strains suffered three days of reduction in viability. After that, the bacteria inoculated with FUY4 showed a thirteen days lag phase, followed by three days of increase in viability and a plateau, whereas the bacteria inoculated with LD80 showed an increase in viability during nine days, followed by a four days plateau and then a decrease in viability. In neither situation did bacterial population show actual growth beyond the initial concentration achieved at inoculation.

In control fermentations, native $O$. oeni reached measurable numbers eight days after yeast inoculation, when the viability of yeasts was already descending. On day 15 , when $\mathrm{AF}$ was complete, native $O$. oeni populations started to decrease in a bimodal fashion: a first step down to $1 \times 10^{6}$ $\mathrm{cfu} / \mathrm{mL}$ that was followed by a one week plateau and then another drop. Native $O$. oeni was more abundant in wine fermented with FUY4 than in wine fermented with LD80. This pattern was maintained throughout the whole alcoholic and malolactic fermentations. In comparison with inoculated bacteria treatments, the populations of native LAB remained at lower levels during most of the examined period.

\section{Chemical parameters in finished wines after completed AF and MLF}

There was a significant interaction between yeast strain and time of bacteria addition regarding residual malic acid $(p=0.001)$. Simultaneous and mid-fermentation inoculation of bacteria and yeast strain LD80 produced the lowest level of residual malic acid, which was significantly lower than in the sequential additions of the bacteria (Table 2). A similar trend was observed for the bacteria inoculated simultaneously with yeast strain FUY4, but in this 

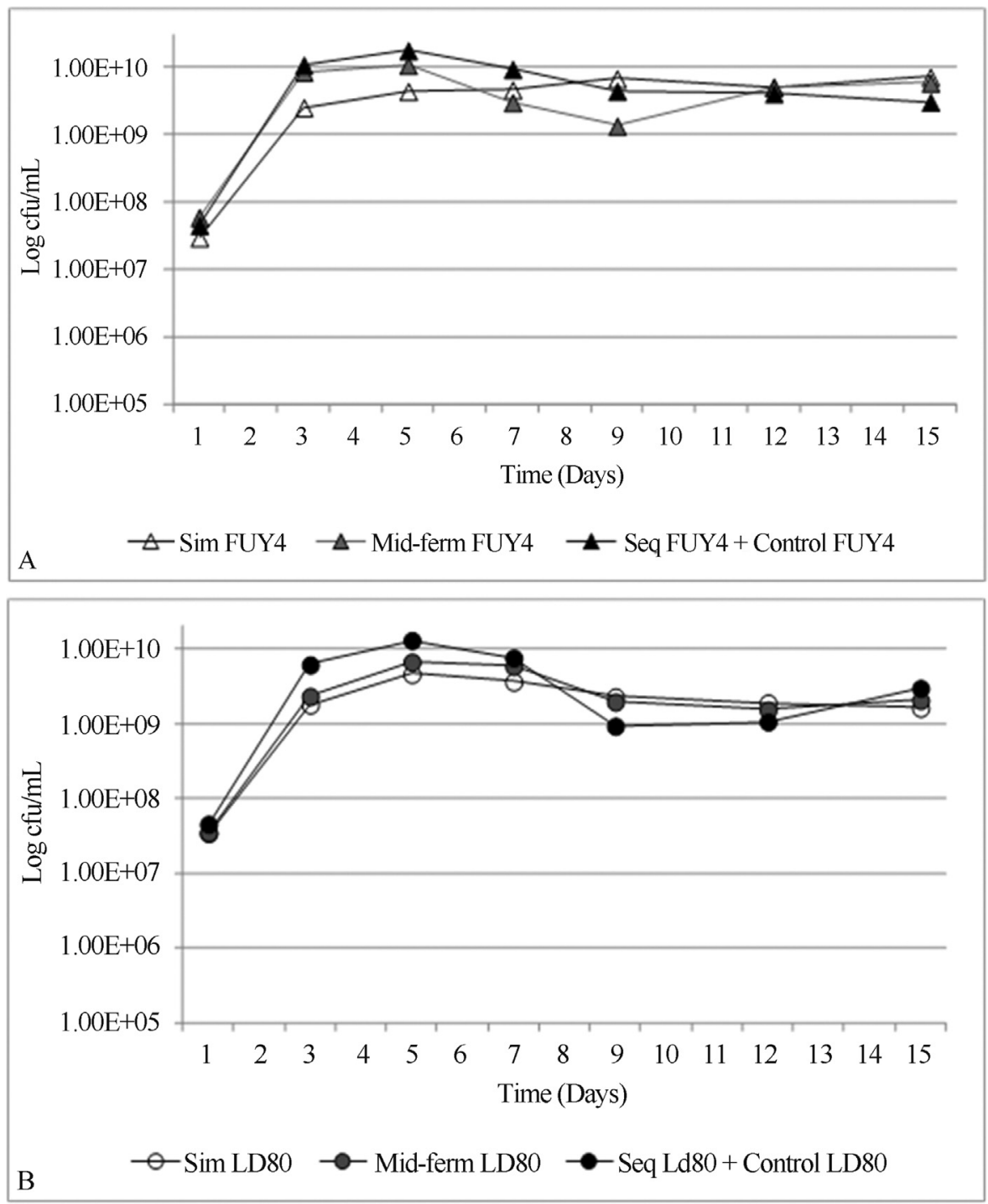

Figure 1 - Viability of S. cerevisiae strains FUY4 (A) and LD80 (B) after simultaneous, mid- fermentation and sequential additions of bacteria. Values are the average of three replicates.

case the sequential addition of bacteria produced the highest level of residual malic acid, more than doubling the levels of any other treatment.

Regarding L-lactic acid, the main effects of yeast strain and time of bacteria inoculation were significant $(p<0.001$ and $p=0.026)$. The wines fermented by FUY 4 consistently showed lower levels than wines fermented with LD80, while both shared a trend towards lower production of L-lactic acid in the mid-fermentation and sequential treatments (Table 2).

D-Lactic produced from the metabolism of sugars indicated a significant interaction between yeast strain and time of bacteria addition $(\mathrm{p}<0.001)$. In wines fermented by LD80, there was a significant effect of the time of bacteria addition: D-lactic was highest at the simultaneous inoculation treatment, lower at the mid fermentation addition and lowest in the sequential inoculation (Table 1). In the case of
FUY4, the timing of addition of bacteria had no significant effect on the level of D-lactic produced, and this level was significantly lower than for LD80 except for the sequential addition of bacteria in which no differences occurred.

Volatile acidity showed a significant interaction between yeast strain and bacteria inoculation $(p=0.001)$. Simultaneous inoculation of LD80 fermented wines produced higher VA than the other treatments. Also, yeast strain effect was only observed for simultaneous and midfermentation inoculations, when wines fermented with LD80 showed significantly higher VA than wines inoculated with FUY4; in sequential inoculations, the differences in VA were not significant (Table 2).

For residual glucose, there was not a significant interaction between factors $(p=0.059)$. Still, FUY4 wines inoculated early with the bacteria had significantly lower residual glucose than wine sequentially inoculated (Ta- 
Table 1 - Length of MLF and AF of musts inoculated with LAB Lalvin VP41 at different times with two yeast strains.

\begin{tabular}{lcc}
\hline Yeast/Time & Length of MLF* & Length of AF** \\
\hline FUY4 Control & 23 & 16 \\
LD80 Control & 25 & 16 \\
FUY4 Simultaneous & 6 & 16 \\
LD80 Simultaneous & 6 & 16 \\
FUY4 Mid-ferm & 7 & 16 \\
LD80 Mid-ferm & 7 & 16 \\
FUY4 Sequential & 20 & 16 \\
LD80 Sequential & 14 & 16 \\
\hline
\end{tabular}

*Days since bacteria addition as determined by the disappearance of the malic acid spot on TLC.

**Days since yeast addition as determined by three consecutive measures bellow $1000 \mathrm{~g} / \mathrm{L}$ with a hydrometer.

ble 2). For LD80 fermented wines, there were no significant differences between wines inoculated with the bacteria at different times. The effect of yeast strain was only significant in simultaneously inoculated wines, when FUY4 wines showed lower residual glucose than LD80 fermented wines .

Regarding residual fructose, there was a significant interaction between yeast strain and time of bacteria inoculation $(\mathrm{p}=0.001)$. Whereas fructose level was significantly higher for LD80 fermented wines in the simultaneous and mid-fermentation treatments than for FUY4 wines, in sequential treatments both reached a similar minimum (Table 2). Alcohol level was not significantly affected by either factor. However, wines fermented with LD80 showed a consistent increase towards later bacterial inoculations.

\section{Discussion}

Interactions between $S$. cerevisiae and $O$. oeni are known to occur during simultaneous fermentations and when MLF takes place after AF. When choosing the early bacterial addition strategy, specific yeast-bacteria interaction might be expected to shift from the patterns that occur in post-fermentation inoculations. Also, within early bacteria additions, the interactions might differ between those observed in simultaneous addition of yeast and bacteria

Table 2 - Main chemical parameters in the finished wine for each yeast strain and time point of bacteria inoculation.

\begin{tabular}{|c|c|c|c|}
\hline & Simultaneous & Mid- fermentation & Sequential \\
\hline \multicolumn{4}{|c|}{ L- Malic acid (mg/L) } \\
\hline FUY4 & $34.770 \pm 5.177 \mathrm{aA}$ & $33.823 \pm 1.085 \mathrm{aA}$ & $81.010 \pm 0.740 \mathrm{aB}$ \\
\hline \multirow[t]{2}{*}{ LD80 } & $29.417 \pm 2.129 \mathrm{bA}$ & $30.367 \pm 0.543 \mathrm{aA}$ & $36.803 \pm 0.006 \mathrm{bB}$ \\
\hline & \multicolumn{3}{|c|}{ L-Lactic $(\mathrm{g} / \mathrm{L})$} \\
\hline FUY4 & $2.179+0.426 \mathrm{aA}$ & $1.862+0.120 \mathrm{aAB}$ & $1.556+0.130 \mathrm{aB}$ \\
\hline \multirow[t]{2}{*}{ LD80 } & $2.713+0.198 \mathrm{bA}$ & $2.670+0.379 \mathrm{bB}$ & $2.369+0.189 b C$ \\
\hline & \multicolumn{3}{|c|}{ D-Lactic (g/L) } \\
\hline FUY4 & $0.443+0.056 \mathrm{aA}$ & $0.459+0.040 \mathrm{aA}$ & $0.395+0.018 \mathrm{aA}$ \\
\hline \multirow[t]{2}{*}{ LD80 } & $0.731+0.065 \mathrm{bA}$ & $0.587+0.037 \mathrm{bB}$ & $0.411+0.033 \mathrm{aC}$ \\
\hline & \multicolumn{3}{|c|}{ Volatile Acidity $\left(\mathrm{g} / \mathrm{L} \mathrm{H}_{2} \mathrm{SO}_{4}\right)$} \\
\hline FUY4 & $0.357+0.024 \mathrm{aA}$ & $0.278+0.009 \mathrm{aB}$ & $0.341+0.036 \mathrm{aA}$ \\
\hline \multirow[t]{2}{*}{ LD80 } & $0.563+0.022 \mathrm{bA}$ & $0.383+0.016 \mathrm{bB}$ & $0.355+0.064 \mathrm{aB}$ \\
\hline & \multicolumn{3}{|c|}{ Glucose $(\mathrm{g} / \mathrm{L})$} \\
\hline FUY4 & $0.002+0.004 \mathrm{aA}$ & $0.011+0.019 \mathrm{aA}$ & $0.075+0.033 \mathrm{aB}$ \\
\hline \multirow[t]{2}{*}{ LD80 } & $0.046+0.037 \mathrm{bA}$ & $0.022+0.021 \mathrm{aA}$ & $0.046+0.008 \mathrm{aA}$ \\
\hline & \multicolumn{3}{|c|}{ Fructose $(\mathrm{g} / \mathrm{L})$} \\
\hline FUY4 & $0.413+0.254 \mathrm{aA}$ & $1.090+0.769 \mathrm{aA}$ & $0.106+0.025 \mathrm{aA}$ \\
\hline \multirow[t]{2}{*}{ LD80 } & $3.906+1.072 \mathrm{bA}$ & $3.518+0.769 \mathrm{bA}$ & $0.084+0.009 \mathrm{aB}$ \\
\hline & \multicolumn{3}{|c|}{ Ethanol $(\% \mathrm{v} / \mathrm{v})$} \\
\hline FUY4 & $13.53+0.06 \mathrm{aA}$ & $13.57+0.06 \mathrm{aA}$ & $13.57+0.15 \mathrm{aA}$ \\
\hline LD80 & $13.43+0.21 \mathrm{aA}$ & $13.67+0.12 \mathrm{aA}$ & $13.73+0.06 \mathrm{aA}$ \\
\hline
\end{tabular}

Values are the mean of three replicates $+/-$ SD.

Different lower case letters within columns indicate significant differences between yeast strains for each time point of bacteria inoculation at $\mathrm{p}=0.05$.

Different capital letters within rows indicate significant differences between time points of bacteria inoculations for each yeast strain at $p=0.05$. 


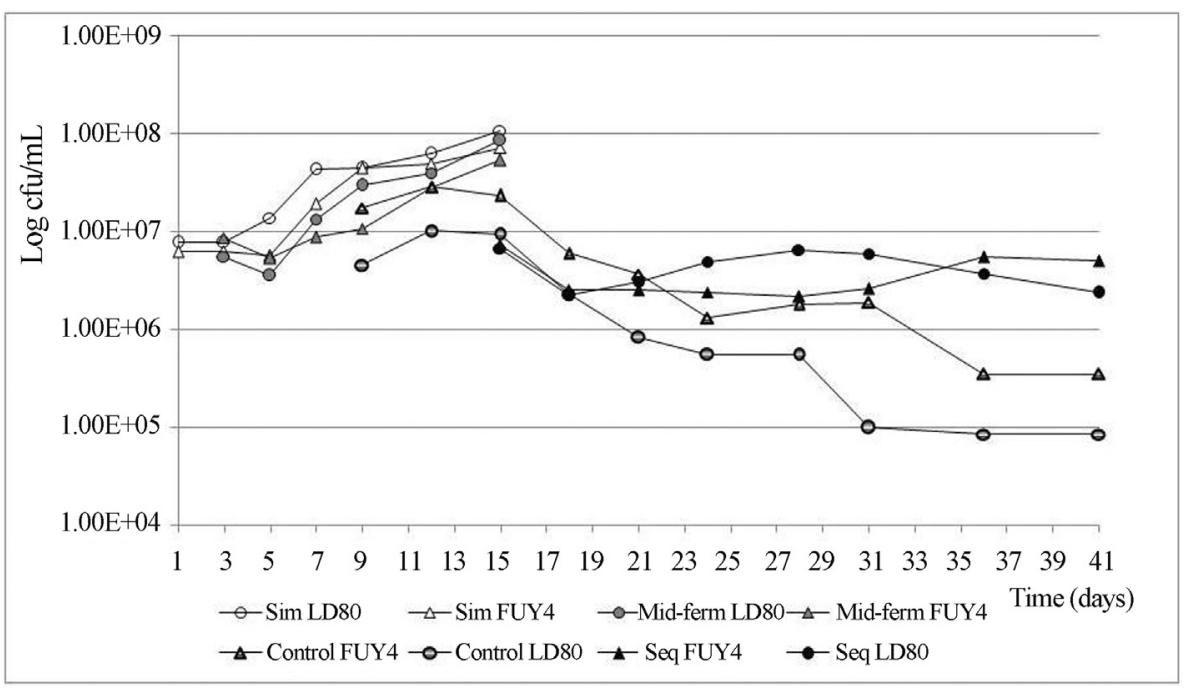

Figure 2 - Viability of inoculated $O$. oeni added at different time points in must inoculated with two strains of S. cerevisiae, and viability of native $O$. oen $i$ in control must inoculated only with yeasts. Values are the average of three replicates.

from those occurring when the bacteria are added in midfermentation.

In our study, the viability of $S$. cerevisiae strains was affected during the occurrence of simultaneous alcoholic and malolactic fermentations. Early addition of bacteria (simultaneous and mid-fermentation treatments) negatively affected both FUY4 and LD80 yeast populations, but the latter showed the most important reduction in cell viability and the highest residual fructose, at a level that indicates the occurrence of a sluggish or stuck fermentation (Bisson and Butzke, 2000). Contrary to previous results that showed no effect (Izquierdo Cañas et al., 2012) or an accelerated yeast cell death after the logarithmic growth phase in simultaneous fermentations (King and Beelman, 1986; Massera et al., 2009), our results suggests that the logarithmic growth phase of the yeast populations was reduced before achieving the stationary phase.

Likewise, bacteria population was also affected by yeasts, and the extent of the effect depended upon both yeast strain and timing of the bacteria inoculation. When the bacteria were simultaneously inoculated with the LD80 yeast strain, they showed the shortest lag phase, the maximum growth and the lowest residual malic acid. When the bacteria were added at mid-fermentation, not a lag phase but a two days initial reduction in bacteria viability was observed with both yeast strains. Also in this case, the wine fermented with LD80 allowed for a faster recovery in viability of the bacteria, and left the smallest amount of residual malic acid although in this case the difference was not statistically significant $(\mathrm{p}=0.098)$. Similarly, King and Beelman (1986) found that bacteria inoculated alone in a model grape juice suffered a short initial lag phase with no loss of viability during $c a .4$ days, but a significant drop in viability occurred when they were inoculated together with yeasts. In our experimental conditions, such a drop was only observed when the bacteria were added to musts that were already fermenting but not in the simultaneous inoculation, so an early inhibition of bacteria by yeasts undergoing their own initial lag phase could not be confirmed.

The number of colonies formed in all early bacterial additions grew beyond the initial inoculation rate, which is indicative of actual growth of the bacterial populations. Bacteria inoculated with FUY4 at mid fermentation did not show actual growth until six days after its inoculation, although its MLF was practically finished by then. Zapparoli et al. (2009) used the same bacterial strain for simultaneous and sequential inoculations with a different yeast strain in a different grape must. They found that the bacteria showed no relevant growth in either situation, and MLF took longer than in the present study. The absence of proliferation and extended MLF they observed could have been due to the initial addition of $50 \mathrm{mg} / \mathrm{L}$ of $\mathrm{SO}_{2}$ to the musts, negative interactions of the VP41 strain with a different strain of $S$. cerevisiae, and also to the different composition of the must.

In the sequential additions of the bacteria, FUY4fermented wine was again less favorable for the inoculated bacteria, which had to undergo an extended thirteen days lag phase and a slower MLF. Noteworthy, final viability of the population achieved by the bacteria with both yeast strains was similar, and equal to the inoculation rate. Therefore, it was confirmed that non-proliferating populations were responsible for the MLF in wines with sequential AF/MLF. This is in agreement with Maicas et al. (2000), who demonstrated that high density inocula about $1 \times 10^{7}$ of non-proliferating $O$. oeni were sufficient to complete MLF in stressful wine conditions.

The duration of MLF differed the most for sequential treatments: 20 days for wines fermented with FUY 4 and 14 days for wines fermented with LD80, while there was no 
difference in the respective early inoculations. Our results in a high alcohol situation like in sequential AF/MLF suggest that for non proliferating populations, a higher level of cell viability can be associated with shorter MLF. In a low alcohol situation with actual population growth (early inoculations), the length of MLF is further reduced. However, this reduction could be due not only to the higher population level achieved by the bacteria, but also to the higher malolactic activity of cells in a medium with less inhibitors. Nehme et al. $(2008,2010)$ concluded that alcohol and a peptidic fraction produced by yeast metabolism contributed to the inhibition of sequential MLF through a reduction in the demalication rate and maximal biomass produced. The fact that the bacterial activity was more affected when it was inoculated with FUY4 than when inoculated with LD80 in three different inoculation strategies (simultaneous, mid-fermentation and end of AF) suggests that the effect of yeast on bacteria was imparted not only by the alcohol produced, but by other compounds that were strain specific and that were present since the beginning of $\mathrm{AF}$, as suggested by Nehme et al. (2010).

From a winemaking perspective, the simultaneous occurrence of both fermentations could be considered problematic in the cases when 3.9 to $3.5 \mathrm{~g} / \mathrm{L}$ of fructose was remnant, that is, in the simultaneous and mid-fermentation addition of bacteria to must fermented by the LD80 yeast strain. This residual level of fructose, although it can be considered still adequate for a dry-style wine, is indicative of a sluggish or stuck fermentation (Bisson and Butzke, 2000; Mendes-Ferreira et al., 2004), and it could be considered a risk factor for the future microbial stability of the wine. In these wines, D-lactic acid produced from hexose degradation by the bacteria was higher than in sequential inoculations. Finally, volatile acidity-mostly acetic acidshowed higher level in wines from simultaneous inoculation with the LD80 yeast strain, similar to the levels observed when grapes suffering from Botrytis rot are vinified (Corison et al., 1979). However, this level was below the legal limit and the aroma threshold for this component (Corison et al., 1979; Zoecklein et al., 1995; Azzolini et al., 2010).

In conclusion, as bacteria in early inoculations in musts with low or no $\mathrm{SO}_{2}$ addition can be expected to multiply and negatively affect specific strains of fermenting yeasts and the completion of alcoholic fermentation, a special consideration should be given not only to the yeastbacterium combination and time point of the inoculation, but also to the amount of bacteria to be inoculated in the favorable conditions of the must. The use of a rather competitive yeast strains or lower bacterial inoculation rates could be envisaged to address this situation. The suitability of yeast-bacteria strains that are compatible for sequential AF/MLF should also be reassessed before they are used in simultaneous fermentations.

\section{Acknowledgments}

Programa Agrario, UTU-CETP for funds. Enol. Jose Lez, Dra. Sandra Lupo and Enól. Fabiana Rodriguez for their help in the planning and critical review of this manuscript.

\section{References}

Abreo E, Etcheverry L (2010) Efecto de la coinoculación de Oenococcus oeni y Saccharomyces cerevisiae sobre el desarrollo de la fermentación alcohólica y maloláctica. In Libro de Memorias XX Congreso Latinoamericano de Microbiología IX Encuentro Nacional de Microbiologos, p 80. Asociación Latinoamericana de Microbiología. Montevideo, Uruguay.

Alexandre HPJ, Costello F, Remize J, Guzzo Guilloux-Benatier M (2004) Saccharomyces cerevisiae-Oenococcus oeni interactions in wine: current knowledge and perspectives. Int $\mathrm{J}$ Food Micro 93:141-154.

Arnink K, Henick-Kling T (2005) Influence of Saccharomyces cerevisiae and Oenococcus oeni strains on successful malolactic conversion in wine. Am J Enol Vitic 56:228-237.

Azzolini M, Tosi E, Vagnoli P, Krieger S, Zapparoli G (2010) Evaluation of technological effects of yeast-bacterial coinoculations in red table wine production. Ital J Food Sci $3: 257-263$.

Beelman RB, Kunkee RE (1985) Inducing simultaneous malolactic - alcoholic fermentations in red table wines. In: Proceedings of the Australian Society of Viticulture and Oenology Seminar on Malolactic Fermentation. pp 97-112. Australian Wine Research Institute, Urrbrae, South Australia (1985).

Bisson L, Butzke C (2000) Diagnosis and rectification of stuck and sluggish fermentations. Am J Enol Vitic 51:168-177.

Corison CA, Ough CS, Berg HW, Nelson KE (1979) Must acetic acid and ethyl acetate as mold and rot indicators in grapes. Am J Enol Vitic 30:130-134.

Davis CR, Wibowo D, Eschenbruch R, Lee TH, Fleet GH (1985) Practical implications of malolactic fermentations: a review. Am J Enol Vitic 36:290-301.

Gerbaux V, Briffox C, Dummont A, Krieger S (2009) Influence of inoculation with malolactic bacteria on volatile phenols in wines. Am J Enol Vitic 60:233-235.

Izquierdo Cañas P, Pérez-Martín F, García Romero E, Seseña Prieto S, Palop Herreros M (2012) Influence of inoculation time of an autochthonous selected malolactic bacterium on volatile and sensory profile of Tempranillo and Merlot wines. International Journal of Food Microbiology 156:245-254.

Jussier D, Morneau AD, Mira de Orduña R (2006) Effect of simultaneous inoculation with yeast and bacteria on fermentation kinetics and key wine parameters of cool-climate Chardonnay. App Env Microb 72:221-227.

King, S.W.; Beelman, R.B. (1986). Metabolic interactions between Saccharomyces cerevisiae and Leuconostoc oenos in a model grape juice/wine system. Am. J. Enol. Vitic. 37:5360 .

Lafon-Lafourcade S, Carre E, Ribérau-Gayon P (1983) Occurrence of lactic acid bacteria during the different stages of 
vinification and conservations of wines. Appl Env Microbiol 46:874-880.

Lonvaud-Funel A (1999) Lactic acid bacteria in the quality improvement and depreciation of wine. Antonie van Leeuwenhoek 76:317-331.

Maicas S, Àngels N, Ferrer S, Pardo I (2000) Malolactic fermentation in wine with high densities of non-proliferating Oenococcus oeni. World J Microbio Biotech 16:805-810.

Martínez C, Cosgaya P, Vásquez C, Gac S, Ganga A (2007) High degree of correlation between molecular polymorphism and geographic origin of wine yeast strains. J App Micro 96:1161-1168.

Massera A, Soria A, Catania C, Krieger S, Combina M (2009) Simultaneous inoculation of Malbec (Vitis vinifera) musts with yeast and bacteria: effects on fermentation performance, sensory and sanitary attributes of wines. Food Technol Biotechnol 47:192-201.

Mendes-Ferreira A, Mendes-Faia A, Leão C (2004) Growth and fermentation patterns of Saccharomyces cerevisiae under different ammonium concentrations and its implications in winemaking industry. J Appl Microbiol 97:540-545.

Mendoza L, Merín M, Morata V, Farías M (2011) Characterization of wines produced by mixed culture of autochthonous yeasts and Oenococcus oeni from the northwest region of Argentina. J Ind Microbiol Biotechnol 38:1777-1785.
Nehme N, Mathieu F, Taillandier P (2008) Quantitative study of interactions between Saccharomyces cerevisiae and Oenococcus oeni strains. J Ind Microbiol Biotechnol 35:685-693.

Nehme N, Mathieu F, Taillandier P (2010) Impact of the coculture of Saccharomyces cerevisiae - Oenococcus oeni on malolactic fermentation and partial characterization of a yeast derived inhibitory peptidic fraction. Food Microbiol 27:150-157.

Pan W, Jussier D, Terrade N, Yada RY, Mira de Orduña R (2011) Kinetics of sugar, organic acids and acetaldehyde during simultaneous yeast-bacterial fermentations of white wine at different $\mathrm{pH}$ values. J Food Res 44:660-666.

Patynowski RV, Jiranek and A, Markides (2002) Yeast viability during fermentation and lees ageing. Aust. J. Grape and Wine Res 8:62-69.

Zapparoli G, Tosi E, Azzolini M, Vagnoli P, Krieger S (2009) Bacterial inoculation strategies for the achievement of malolactic fermentation in high-alcohol wines. S Afr J Enol Vitic 30:49-55.

Zoecklein BV, Fugelsang KC, Gump BH, Nury FS (1995) Wine Analysis and production. Chapman \& Hall, New York, USA.

All the content of the journal, except where otherwise noted, is licensed under a Creative Commons License CC BY-NC. 